The International Journal Of Engineering And Science (IJES)

|| Volume || 6 || Issue || 1 || Pages || PP 22-33 || 2017 ||

ISSN (e): $2319-1813$ ISSN (p): $2319-1805$

THE IJES

\title{
Modelling of Corrosion Inhibition of Mild Steel in Hydrochloric Acid by Crushed Leaves of Sida Acuta (Malvaceae)
}

\author{
Agha Inya Ndukwe ${ }^{1}$ and C. N. Anyakwo ${ }^{2}$ \\ ${ }^{I}$ Department of Metallurgical Engineering Technology, Akanu Ibiam Federal Polytechnic Unwana, P.M.B. \\ 1007, Afikpo, Nigeria. \\ ${ }^{2}$ Department of Materials and Metallurgical Engineering, Federal University of Technology, P.M.B. 1526, \\ Owerri, Nigeria.
}

\begin{abstract}
The corrosion inhibition of mild steel in $0.7 \mathrm{M}, 1.2 \mathrm{M}$ and $2.2 \mathrm{M} \mathrm{HCl}$ by thoroughly pounded fresh leaves of Sida Acuta has been investigated using the weight-loss method. Corrosion rate curves progressively decreased with time. The maximum inhibition efficiency of $71.16 \%$ was attained when the crushed leaves of Sida Acuta were added at $15 \mathrm{~g}$ per litre of $0.7 \mathrm{M} \mathrm{HCl}$ whilst the corrosion rate reduced from 1.0485 to $0.3006 \mathrm{mgcm}^{-2} \mathrm{~h}^{-1}$. The predictive corrosion rate model was developed using multiple regression and artificial neural network. Predictions of the experimental corrosion rate values by the artificial neural network revealed the importance of independent variables: (time $(h)$, concentration of acid $(M)$ and quantity of extract $(g))$ in the prediction of the dependent variable (Corrosion rate, $C R\left(\mathrm{mgcm}^{-2} \mathrm{~h}^{-1}\right)$. The time of exposure immensely contributed to the prediction of the experimental corrosion rate by $48.9 \%$, followed by the quantity of crushed leaves, $26.2 \%$ and finally the concentration of acid, 25.0\%. Predictions by the artificial neural network gave minimal errors and were closer to the experimental corrosion rate values in comparison with the predictions by multiple regression. The protective film formed on the mild steel surface was analysed by FTIR spectroscopy and surface electron microscopy (SEM). The FTIR analysis revealed that the adsorbed constituents of the pounded fresh leaves of Sida Acuta on the surface of mild steel were associated with the stretching vibrations of $C \equiv C, C=C, C=O$ and $O-H$ bonds. The SEM image shows that the degradation of the surface of mild steel in an uninhibited solution of $0.7 \mathrm{M} \mathrm{HCl}$ is localized but the addition of the inhibitor remarkably prevented the surface of mild steel from corrosion. Four adsorption isotherm models were tested and the results show that the corrosion inhibition of mild steel by the crushed fresh leaves of Sida Acuta in hydrochloric acid obeys all the isotherm models with the Langmuir adsorption isotherm maintaining the best fit of $R^{2}=0.996$; El-Awady, $R^{2}=0.961$; Temkin, $R^{2}=$ 0.952 and Freundlich, $R^{2}=0.942$. The phytochemical analysis of Sida Acuta's leaves disclosed the presence of alkanoid, tannin, saponin, phytate, flavonoid and phenol.
\end{abstract}

Keywords: Corrosion rate; Inhibition efficiency; Sida Acuta; Crushed fresh leaves; FTIR analysis; SEM image; Multiple regression; Artificial neural network

Date of Submission: 11 January 2016

\section{INTRODUCTION}

Corrosion is an unwanted oxidation of a metal. It cuts short the lifetime of steel products such as bridges and automobiles; replacing corroded metal parts costs billions of dollars a year. Corrosion is an electrochemical process, and the electrochemical series gives us insight into why corrosion occurs and how it can be prevented (Jones and Atkins, 2000, p.821). Corrosion inhibition is a veritable measure that is employed to combat corrosion. A substance that is able to prevent the corrosion of any metal or alloy when added in minute quantity to the corrodent is an inhibitor. Corrosion inhibitors are added to a corrosion system to decrease or eliminate anodic dissolution; a good example of their application is in acid pickling operations that are employed to remove oxide scales formed during metal working operations (Anyakwo, 2007, p. 8). All the same, an inhibitor hinders corrosion reactions either by reducing the probability of corrosion occurrence or by reducing the rate of attack or both (Raja and Sethuraman, 2008).

The toxic nature of the known effective inhibitors that are chromate and arsenate-based has led to the study of various alternative means of corrosion inhibition. Plant-leaf extracts have shown promise in inhibiting the corrosion of mild steel in acidic medium. According to (Patni et al., 2013), plant extracts contain many organic compounds that have polar atoms such as $\mathrm{O}, \mathrm{P}, \mathrm{S}$ and $\mathrm{N}$ which adsorb on the metal surface to form protective films. However, the corrosion inhibition of mild steel by thoroughly crushed fresh leaves of Sida Acuta is relevant to this present study. 
Sida Acuta is a small, erect, perennial shrub, branching profusely from the base. It usually ranges from $30-150 \mathrm{~cm}$ in height, but grows to $3 \mathrm{~m}$ in favourable conditions in northern Australia (Lonsdale et al., 1995). The stems are almost woody, with a tough stringy bark. There is a deep, tough taproot. The leaves are alternate, lanceolate, acute, tapering towards both ends, and on a short, hairy petiole $3-6 \mathrm{~mm}$ long. The leaves have toothed margins, smooth or sparse stellate hairs and prominent veins on the under surface. The leaves are quite variable in size, from $2-9 \mathrm{~cm}$ long and $0.5-4 \mathrm{~cm}$ wide. The pair of stipules at the base of each leaf is not equal, with one frequently much narrower than the other. Sida Acuta is found on most soil types, except seasonally flooded clays or soils derived from limestone (Rojas-Sandoval et al., 2009). It competes vigorously with other plant species, but does best in tropical or sub-tropical regions with a distinct wet and dry season. It has a deep taproot and can withstand drought, mowing and shallow tillage. It is a weed of degraded pastures, tree plantations, cereals, root crops, vegetables, planted forests, lawns, roadsides, and waste places (Pitt, 1992; Flanagan et al., 2000). In habitats where it occurs, it tends to flourish in riparian areas near watercourses. It has been reported at up to $1500 \mathrm{~m}$ altitude in Indonesia, at medium and higher elevations in Kenya and in the foothills of the Andes in Peru (Rojas-Sandoval et al., 2009).

Investigation of Sida Acuta (wireweed) plant extract as corrosion inhibitor for aluminium-coppermagnesium alloy in acidic medium was carried out by (Ayeni et al., 2014, p. 286). They reported that the presence of Sida Acuta plant extract reduced corrosion rate from 0.0012 to $0.0001 \mathrm{mpy}$ and percentage protection increased from $37.42 \%$ to $93.63 \%$ within a ten-day period with increase in percentage volume of the extract.

Further analysis of the surface of mild steel with and without the presence of an inhibitor can be done using Fourier Transform infrared (FTIR) Spectrometer and Scanning Electron Microscope (SEM). The FTIR spectrometer is used to figure out the type of bonding, particularly functional groups present in organic compounds. It is useful in predicting whether organic inhibitors are adsorbed or not on the metal surface. On the other hand, the SEM produces black and white, three-dimensional images. Image magnification can be up to 10 nanometres and the intense interactions that take place on the surface of the specimen provide a greater depth of view, higher-resolution and ultimately, a more detailed surface picture (Scanning Electron Microscopy, 2016).

In corrosion inhibition study, a predictive model presents a well-informed relationship between the acid induced corrosion and the rate of corrosion after the addition of an inhibitor. Mathematical models are designed to describe physical systems by equations or, more in general, by logical and computational structures (Bellomo et al., 2007). However, system modelling and simulation of the actual physical system offer a better alternative in situations where research facilities are in short supply and in some cases non-existent (Okoro, 2008). Multiple regression is an extension of simple linear regression. It is used when we want to predict the value of a variable, based on the value of two or more other variables. (Lærd, 2013, para. 1).

\section{MATERIALS AND METHODS}

\subsection{Fabrication of mild steel coupons}

Mild steel coupons of $40 \mathrm{~mm} \times 40 \mathrm{~mm} \times 1.5 \mathrm{~mm}$ dimensions were cut from a sheet metal with the following composition (wt \%) $\mathrm{C}=0.20 \%, \mathrm{Zn}=0.75 \%, \mathrm{Ti}=0.28, \mathrm{Mn}=0.23 \%, \mathrm{~S}=0.04 \%, \mathrm{P}=0.035 \%$ and $\mathrm{Fe}$ balance. The initial weight of each specimen was measured using the Ohaus electronic weighing balance before immersion.

\subsection{Weight-loss experimentation}

Sida Acuta's leaves, obtained within the immediate vicinity of the Federal University of Technology, Owerri were thoroughly pounded and added to the hydrochloric acid solution at $15 \mathrm{~g}$ per litre, $30 \mathrm{~g}$ per litre and $45 \mathrm{~g}$ per litre of $0.7 \mathrm{M}, 1.2 \mathrm{M}$ and $2.2 \mathrm{M} \mathrm{HCl}$. The acid concentration was prepared using dilution formula. Meanwhile, a different experimental set-up was prepared wherein no inhibitor was added in order to serve the purpose of comparison. Each experiment lasted for eight hours. In addition, the moisture content of the freshleaves of Sida Acuta was about $64.77 \%$ as at the time of the experiment was conducted.

The corrosion rate, CR was calculated by using the formula (Fadare et al., 2016):

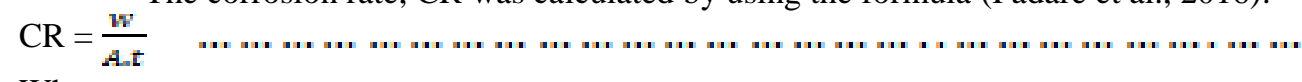

Where,

$w=$ weight loss in $g$.

$A=$ exposed area in $\mathrm{cm}^{-2}$.

$t=$ exposure time in hours.

The corrosion inhibition efficiency was obtained by the relationship:

Inhibition Efficiency, I.E $(\%)=\left(\left(C R_{u n}-C R_{\text {in }}\right) / C R_{u n}\right) \times 100 \ldots$

Where,

$C R_{u n}=$ Corrosion Rate of the uninhibited system.

$C R_{\text {in }}=$ Corrosion Rate of the inhibited system. 


\subsection{Analysis of experimental data}

\subsubsection{Multiple regression (MR)}

Regression analysis is a statistical tool for the investigation of relationships between variables (Sykes, 1992). According to (Lærd Statistics, 2013), multiple regression is an extension of simple linear regression. It is used when we want to predict the value of a variable based on the value of two or more other variables. The variable we want to predict is called the dependent variable (or sometimes, the outcome, target or criterion variable). The variables we are using to predict the value of the dependent variable are called the independent variables (or sometimes, the predictor, explanatory or regressor variables).

The formula for multiple regression is stated thus (Higgins, 2005):

$\mathrm{Y}^{*}=\mathrm{a}+\mathrm{b}_{1} \mathrm{X}_{1}+\mathrm{b}_{2} \mathrm{X}_{2}+\cdots+\mathrm{b}_{\mathrm{n}} \mathrm{X}_{\mathrm{n}}$

Where,

$Y^{*}=$ the predicted value of $Y$ (which is the dependent variable).

$a=$ the ' $Y$ intercept'.

$b_{1}=$ the change in $Y$ for each 1 increment change in $X_{1}$.

$b_{2}=$ the change in $Y$ for each 1 increment change in $X_{2}$.

$X_{1}=$ an $X$ score on your first independent variable for which you are trying to predict a value of $Y$.

$X_{2}=$ an $X$ score on your second independent variable for which you are trying to predict a value of $Y$.

\subsubsection{Artificial neural network}

Artificial neural networks (ANNs) are computer models inspired by the structure of biological neural networks. They consist of highly interconnected nodes, and their overall ability to help predict outcomes is determined by the connections between these neurons (Ayer et al., 2010, p. 15). ANNs are capable of 'learning', that is, they use experience to improve their performance. When exposed to a sufficient number of samples, ANNs can generalise to others they have not yet encountered.

An artificial neural network consists of a number of very simple and highly interconnected processors, also called neurons, which are analogous to the biological neurons in the brain. The neurons are connected by weighted links passing signals from one neuron to another. Each neuron receives a number of input signals through its connections; however, it never produces more than a single output signal. The output signal is transmitted through the neuron's outgoing connection (corresponding to the biological axon). The outgoing connection, in turn, splits into a number of branches that transmit the same signal (the signal is not divided among these branches in any way). The outgoing branches terminate at the incoming connections of other neurons in the network. A schematic representation of artificial neural network model representing inputs and output for this present study is displayed in Figure 1.

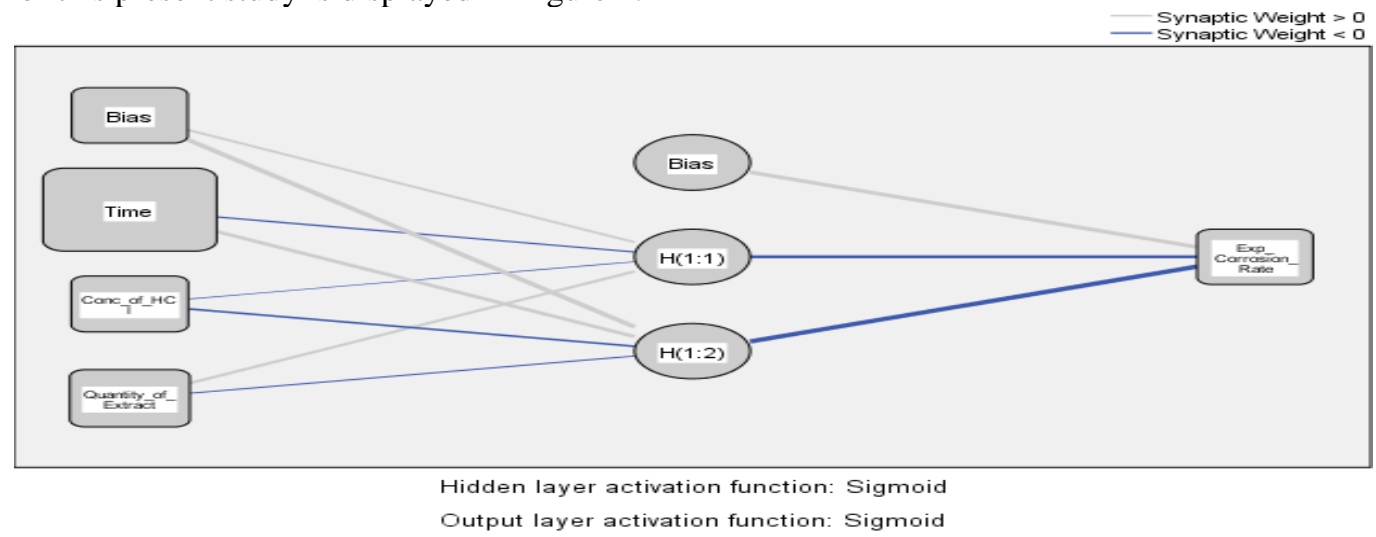

Figure 1: Schematic representation of artificial neural network model representing inputs and output.

Given a unit, $\mathrm{j}$ in a hidden or output layer, the net input, $\mathrm{I}_{\mathrm{j}}$, to unit $\mathrm{j}$ is (Han et al., 2012):

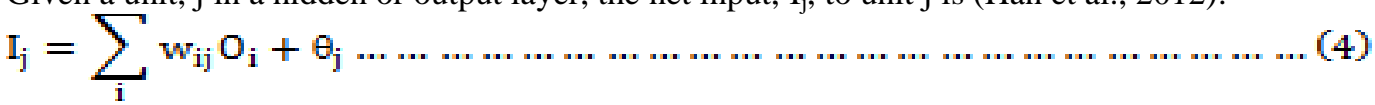

Where,

$w_{i j}$ is the weight of the connection from unit $i$ in the previous layer to unit $j$.

$O_{i}$ is the output of unit $i$, from the previous layer.

$\theta_{j}$ is the bias of the unit. The bias acts as a threshold in that it serves to vary the activity of the unit. This function is also referred to as a squashing function, because it maps a large input domain onto the smaller range of 0 to 1 (Han et al., 2012). 
Given the net input $\mathrm{I}_{\mathrm{j}}$ to unit $\mathrm{j}$, then $\mathrm{O}_{\mathrm{j}}$, the output of unit $\mathrm{j}$, is computed as: $o_{j}=\frac{1}{1+\mathrm{e}^{-\mathrm{I}_{\mathrm{j}}}}$

\subsubsection{Evaluation of error in prediction}

The mean absolute error (MAE) and mean squared error (MSE) are used to figure out how close a predicted value is to the actual value. The formula for computing the mean absolute error is given by (Mean Absolute Error, 2016):

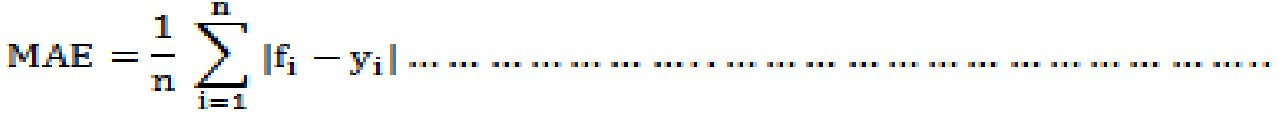

Where,

$f_{i}=$ the predicted value.

$y_{i}=$ the true value

Mathematically, the mean squared error is represented thus (Mean Squared Error and Residual Sum of Squares, 2013):

MSE $=\frac{1}{\mathrm{~N}} \sum\left(\mathrm{f}_{\mathrm{i}}-\mathrm{y}_{\mathrm{i}}\right)^{2}$

Where

$N=$ number of samples.

$f_{i}=$ an estimator of parameter $y_{i}$.

$y_{i}=$ true value.

\section{RESULTS}

Table 1: Effect of addition of thoroughly pounded Sida Acuta's fresh leaves on the corrosion of mild steel coupons immersed in hydrochloric acid solution

\begin{tabular}{|c|c|c|c|c|c|c|}
\hline \multirow{2}{*}{$\begin{array}{c}\text { Exposure } \\
\text { Time } \\
(h)\end{array}$} & \multicolumn{2}{|c|}{$0.7 \mathrm{M} \mathrm{HCl}$} & \multicolumn{2}{|c|}{$1.2 \mathrm{M} \mathrm{HCl}$} & \multicolumn{2}{|c|}{$2.2 \mathrm{M} \mathrm{HCl}$} \\
\hline & $\begin{array}{c}C R \\
\left(\mathrm{mgcm}^{-2} h^{-1}\right)\end{array}$ & $\begin{array}{c}\boldsymbol{I} \cdot \boldsymbol{E} \\
(\%)\end{array}$ & $\begin{array}{c}C R \\
\left(\mathrm{mgcm}^{-2} h^{-1}\right)\end{array}$ & $\begin{array}{l}I . E \\
(\%)\end{array}$ & $\begin{array}{c}C R \\
\left(\mathrm{mgcm}^{-2} h^{-1}\right)\end{array}$ & $\begin{array}{l}\boldsymbol{I} \boldsymbol{E} \\
(\%)\end{array}$ \\
\hline \multicolumn{7}{|c|}{ Addition of crushed leaves of Sida Acuta at $15 \mathrm{~g}$ per litre of $\mathrm{HCl}$} \\
\hline 1 & 1.0485 & 60.41 & 1.4638 & 35.96 & 4.1154 & 30.98 \\
\hline 2 & 0.5925 & 68.22 & 0.9018 & 42.50 & 2.2973 & 35.69 \\
\hline$\frac{2}{3}$ & 0.4608 & 67.06 & 0.7803 & 29.76 & 1.5393 & 36.83 \\
\hline 4 & 0.4378 & 69.03 & 0.7065 & 39.89 & 1.2082 & 36.58 \\
\hline 5 & 0.4037 & 71.60 & 0.6901 & 41.70 & 0.9921 & 36.74 \\
\hline 6 & 0.3006 & 78.03 & 0.6999 & 33.15 & 0.8766 & 34.88 \\
\hline 7 & 0.3145 & 77.41 & 0.6647 & 36.37 & 0.7560 & 37.08 \\
\hline 8 & 0.3129 & 77.54 & 0.5805 & 37.42 & 0.7435 & 35.85 \\
\hline Average & 0.4839 & 71.16 & 0.8110 & 37.09 & 1.5661 & 35.58 \\
\hline \multicolumn{7}{|c|}{ Addition of crushed leaves of Sida Acuta at $30 \mathrm{~g}$ per litre of $\mathrm{HCl}$} \\
\hline 1 & 1.1792 & 55.48 & 1.7106 & 25.16 & 3.9847 & 33.17 \\
\hline 2 & 0.7275 & 60.98 & 0.8103 & 48.33 & 2.0853 & 41.63 \\
\hline 3 & 0.4724 & 66.23 & 0.6089 & 45.19 & 1.3205 & 45.81 \\
\hline 4 & 0.4821 & 65.90 & 0.7740 & 34.14 & 1.0615 & 44.28 \\
\hline$\frac{7}{5}$ & 0.4200 & 70.43 & 0.5826 & 50.79 & 0.8051 & 48.66 \\
\hline 6 & 0.4478 & 67.28 & 0.4811 & 54.05 & 0.6583 & 51.10 \\
\hline 7 & 0.3946 & 71.66 & 0.3502 & 66.48 & 0.5145 & 57.18 \\
\hline 8 & 0.3590 & 74.24 & 0.3471 & 62.58 & 0.4531 & 60.66 \\
\hline Average & 0.5603 & 66.53 & 0.7081 & 48.34 & 1.3604 & 47.81 \\
\hline \multicolumn{7}{|c|}{ Addition of crushed leaves of Sida Acuta at $45 \mathrm{~g}$ per litre of $\mathrm{HCl}$} \\
\hline 1 & 1.8210 & 31.25 & 1.2359 & 45.93 & 4.0341 & 32.34 \\
\hline$\frac{2}{2}$ & 0.7667 & 58.88 & 0.9221 & 41.20 & 1.8544 & 48.09 \\
\hline 3 & 0.7087 & 49.39 & 0.3892 & 64.97 & 1.3457 & 44.77 \\
\hline 4 & 0.6190 & 56.21 & 0.2316 & 80.29 & 1.1726 & 38.45 \\
\hline$\frac{7}{5}$ & 0.4740 & 66.65 & 0.3694 & 68.80 & 0.9416 & 39.96 \\
\hline 6 & 0.4903 & 64.17 & 0.4013 & 61.67 & 0.8694 & 35.42 \\
\hline 7 & 0.3118 & 77.61 & 0.3170 & 69.66 & 0.5846 & 51.35 \\
\hline 8 & 0.2672 & 80.82 & 0.2676 & 71.15 & 0.5290 & 54.08 \\
\hline Average & 0.6823 & 60.62 & 0.5168 & 62.96 & 1.4164 & 43.06 \\
\hline
\end{tabular}




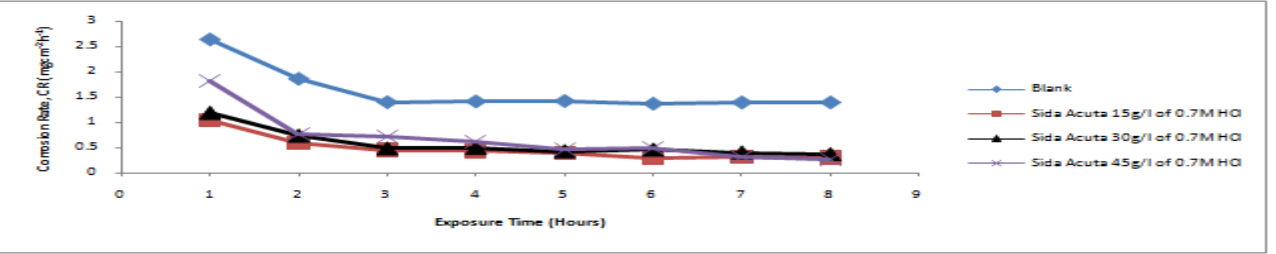

(a)

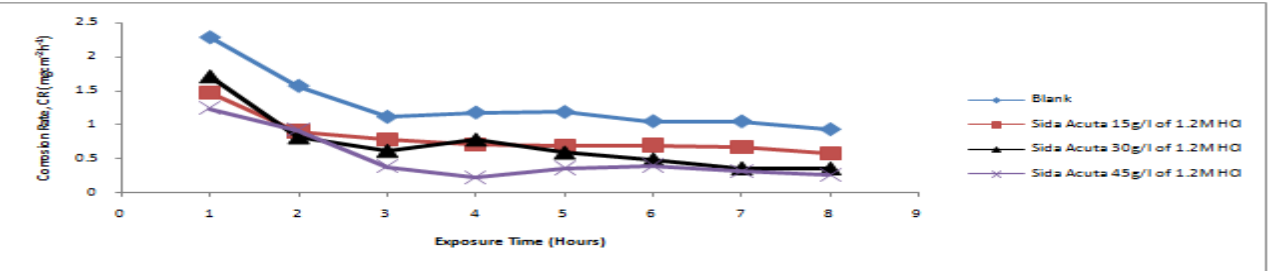

(b)

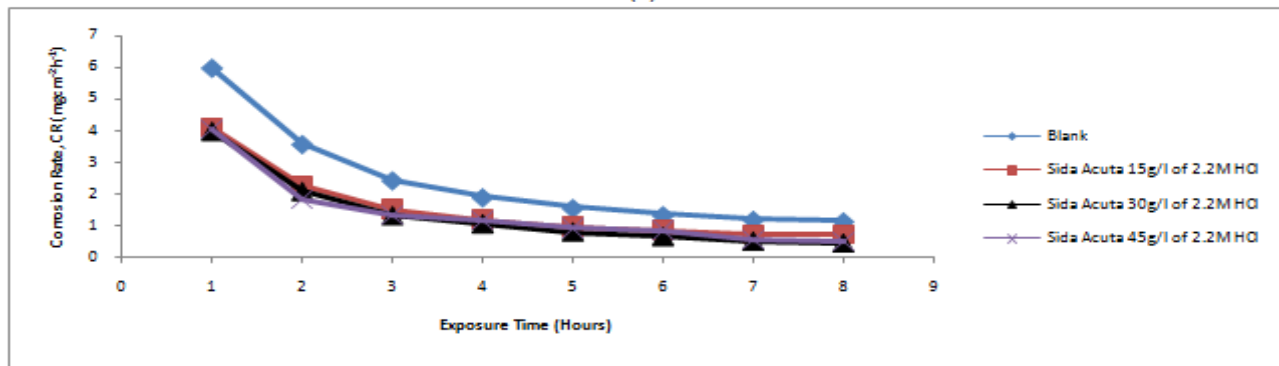

(c)

Figure 2: Effect of addition of thoroughly pounded fresh leaves of Sida Acuta on corrosion of mild steel coupons immersed at:
(a) $15 \mathrm{~g} / \mathrm{l}, 30 \mathrm{~g} / \mathrm{l}$ and $45 \mathrm{~g} / \mathrm{l}$ of $0.7 \mathrm{M} \mathrm{HCl}$
(b) $15 \mathrm{~g} / \mathrm{l}, 30 \mathrm{~g} / \mathrm{l}$ and $45 \mathrm{~g} / \mathrm{l}$ of $1.2 \mathrm{M} \mathrm{HCl}$
(c) $15 \mathrm{~g} / \mathrm{l}, 30 \mathrm{~g} / \mathrm{l}$ and $45 \mathrm{~g} / \mathrm{l}$ of $2.2 \mathrm{M} \mathrm{HCl}$

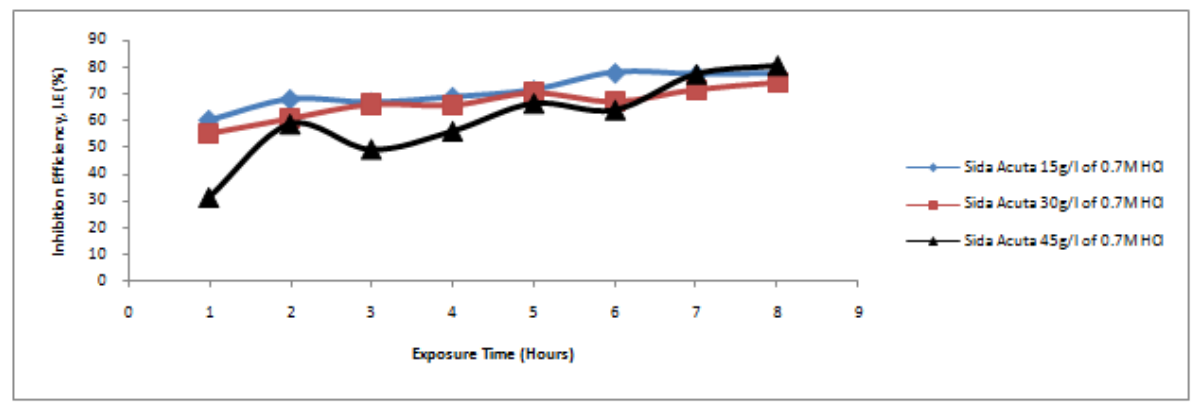

(a)

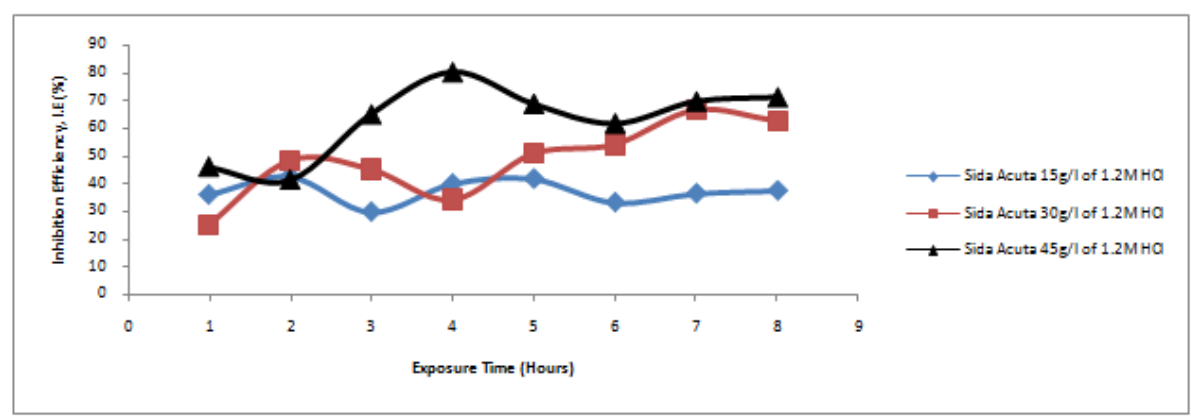

(b) 


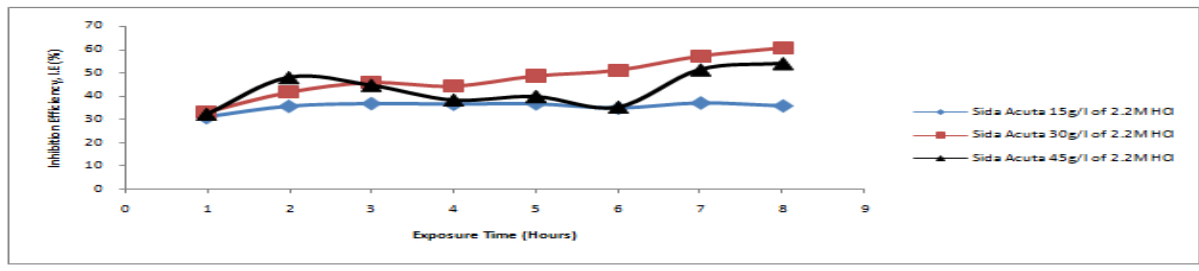

Figure 3: Sida Acuta's corrosion inhibition efficiency for mild steel coupons immersed at:

(a) $15 \mathrm{~g} / \mathrm{l}, 30 \mathrm{~g} / \mathrm{l}$ and $45 \mathrm{~g} / \mathrm{l}$ of $0.7 \mathrm{M} \mathrm{HCl}$

(b) $15 \mathrm{~g} / \mathrm{l}, 30 \mathrm{~g} / \mathrm{l}$ and $45 \mathrm{~g} / \mathrm{l}$ of $1.2 \mathrm{M} \mathrm{HCl}$

(c) $15 \mathrm{~g} / \mathrm{l}, 30 \mathrm{~g} / \mathrm{l}$ and $45 \mathrm{~g} / \mathrm{l}$ of $2.2 \mathrm{M} \mathrm{HCl}$

Table 2: Analysis for prediction of corrosion inhibition of mild steel by the crushed leaves of Sida Acuta in hydrochloric acid medium using multiple regression (MR)

\begin{tabular}{|l|l|l|l|l|}
\hline \multirow{2}{*}{} & \multicolumn{3}{|c|}{ Model Coefficients } \\
\cline { 2 - 5 } & Constant & $\begin{array}{l}\text { Time } \\
\text { (h) }\end{array}$ & $\begin{array}{l}\text { Conc. of Acid } \\
\text { (M) }\end{array}$ & $\begin{array}{l}\text { Quantity of Crushed } \\
\text { Leaves } \\
\text { (g) }\end{array}$ \\
\hline HCl & 1.721 & -0.229 & 0.618 & -0.019 \\
\hline
\end{tabular}

Table 3: Analysis for prediction of corrosion inhibition of mild steel by the crushed leaves of Sida Acuta in hydrochloric acid medium using artificial neural network (ANN)

Independent variable importance for the addition of crushed fresh leaves of Sida Acuta in hydrochloric acid solution

\begin{tabular}{|l|c|c|}
\hline & Importance & Normalized Importance \\
\hline Time_of_Exposure & 0.489 & $100.0 \%$ \\
Conc_of_HCl & 0.250 & $51.2 \%$ \\
Quantity_of_Crushed_Leaves & 0.262 & $53.5 \%$ \\
\hline
\end{tabular}

Parameter estimates for the addition of crushed fresh leaves of Sida Acuta in hydrochloric acid solution

\begin{tabular}{|c|c|c|c|c|}
\hline & \multirow{3}{*}{ Predictor } & \multicolumn{3}{|c|}{ Predicted } \\
\hline & & \multicolumn{2}{|c|}{ Hidden Layer 1} & \multirow{2}{*}{$\begin{array}{c}\text { Output Layer } \\
\text { Exp_Corrosion_Rate }\end{array}$} \\
\hline & & $\mathrm{H}(1: 1)$ & $\mathrm{H}(1: 2)$ & \\
\hline \multirow{4}{*}{ Input Layer } & (Bias) & 1.252 & 4.144 & \\
\hline & Time & -0.214 & 2.412 & \\
\hline & Conc_of_HCl & -0.156 & -1.075 & \\
\hline & $\begin{array}{l}\text { Quantity_of_Crushed_Leaves } \\
\text { (Bias) }\end{array}$ & 2.012 & -0.180 & 3.313 \\
\hline \multirow[t]{2}{*}{ Hidden Layer 1} & $H(1: 1)$ & & & -2.067 \\
\hline & $\mathrm{H}(1: 2)$ & & & -4.518 \\
\hline
\end{tabular}

Table 4: Error analysis for the prediction of corrosion inhibition of mild steel by thoroughly pounded leaves of Sida Acuta in hydrochloric acid solution using multiple regression, MR and artificial neural network, ANN

\begin{tabular}{|l|l|l|}
\hline Error & $\begin{array}{l}\text { Prediction of CR by } \\
\text { Multiple Regression, MR }\end{array}$ & Prediction of CR by Artificial Neural Network, ANN \\
\cline { 2 - 3 } & & \\
\hline Mean Absolute Error & 0.42538125 & 0.202978125 \\
\hline Mean Squared Error & 0.378324713 & 0.078711839 \\
\hline
\end{tabular}

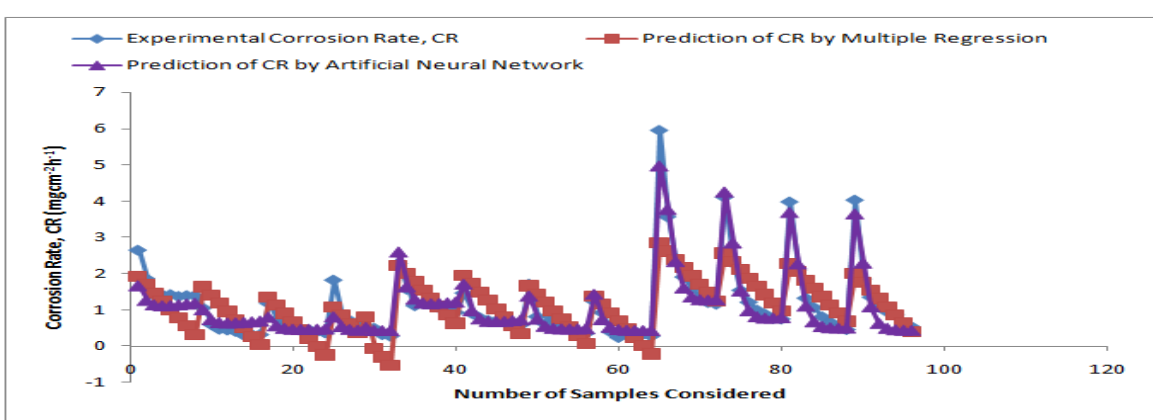

Figure 4: Comparison of error for the prediction of corrosion inhibition of mild steel by thoroughly crushed leaves of Sida Acuta in hydrochloric acid using multiple regression, MR and artificial neural network, ANN 


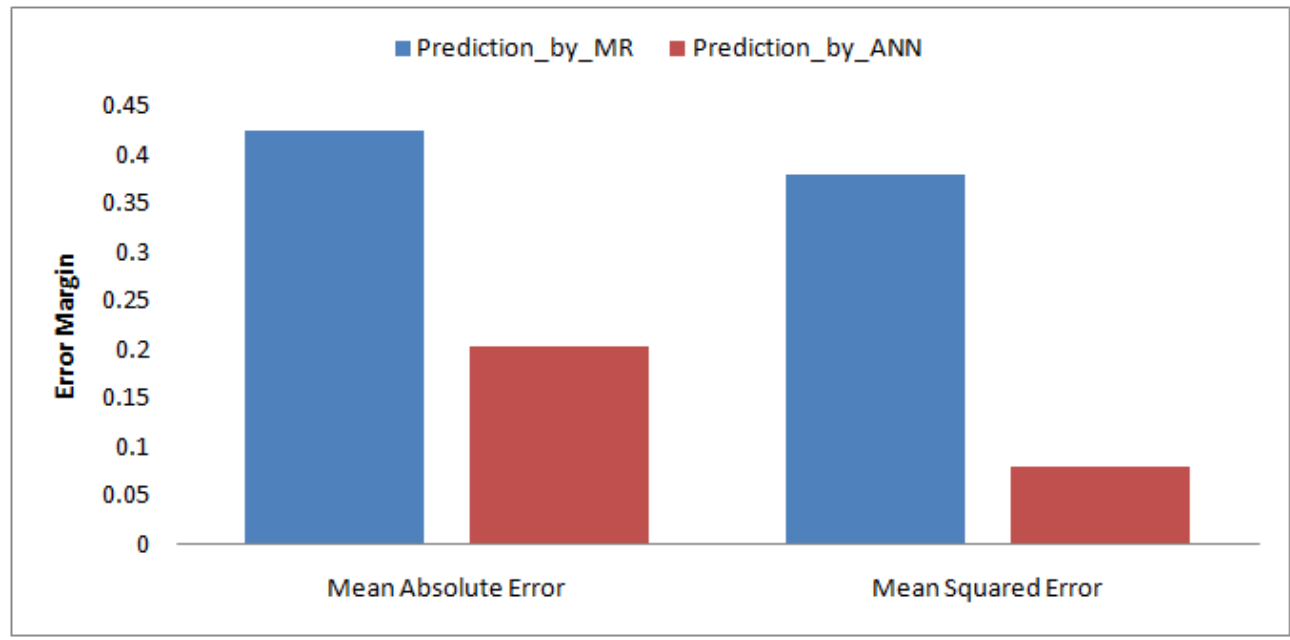

Figure 5: Error graph for the prediction of corrosion inhibition of mild steel in hydrochloric acid by thoroughly crushed leaves of Sida Acuta using multiple regression, MR and artificial neural network, ANN

Table 5: Effect of variation in temperature on the corrosion of mild steel coupons immersed in $0.7 \mathrm{M} \mathrm{HCl}$ without and with $15 \mathrm{~g}$ of thoroughly crushed Sida Acuta's fresh leaves

Slope $_{\text {Blank }}=-1092 \mathrm{~K}^{-1}$

\begin{tabular}{|l|l|l|l|l|l|}
\hline $\begin{array}{l}\text { Temperature } \\
(\mathbf{K})\end{array}$ & $\begin{array}{l}\mathbf{C R}_{\text {SA addition }} \\
\left(\mathbf{m g c m}^{-2} \mathbf{h}^{-\mathbf{1}}\right)\end{array}$ & $\begin{array}{l}\mathbf{C R}_{\text {Blank }} \\
\left(\mathbf{m g c m}^{-\mathbf{2}} \mathbf{h}^{\mathbf{- 1}}\right)\end{array}$ & Log $\mathbf{C R}_{\text {SA addition }}$ & Log CR Blank & $\begin{array}{l}\mathbf{1 / T} \\
\left(\mathbf{K}^{-\mathbf{1}}\right)\end{array}$ \\
\hline 298 & 0.4839 & 1.6127 & -0.3152 & 0.2076 & 0.003356 \\
\hline 318 & 1.7391 & 5.4985 & 0.2403 & 0.7402 & 0.003145 \\
\hline 338 & 2.6057 & 6.4186 & 0.4159 & 0.8074 & 0.002959 \\
\hline 358 & 3.3718 & 7.0779 & 0.5279 & 0.8499 & 0.002793 \\
\hline
\end{tabular}

Activation Energy, $\mathbf{Q}=20,908.68 \mathrm{~J}$
Slope $_{S A}$ addition $=-1467 \mathrm{~K}$

Activation Energy, $\mathbf{Q}=28,088.86 \mathrm{~J}$

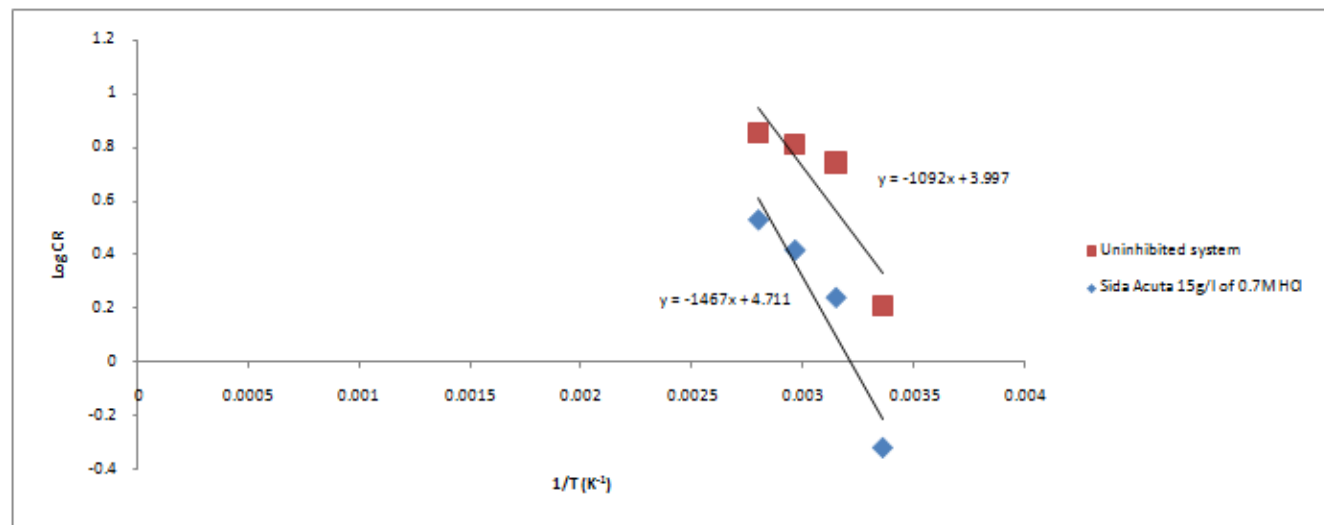

Figure 6: Arrhenius plot for the effect of variation in temperature on the corrosion of mild steel coupons immersed in $0.7 \mathrm{M} \mathrm{HCl}$ without and with $15 \mathrm{~g}$ of thoroughly crushed Sida Acuta's fresh leaves

Table 6: Calculated parameters of four adsorption isotherm models for adsorption of the thoroughly crushed fresh leaves of Sida Acuta onto the Surface of Mild Steel in Hydrochloric Acid medium.

\begin{tabular}{|c|c|c|c|c|c|c|c|}
\hline \multicolumn{8}{|c|}{ Adsorption Isotherm } \\
\hline \multicolumn{2}{|c|}{ Langmuir } & \multicolumn{2}{|c|}{ Freundlich } & \multicolumn{2}{|l|}{ Temkin } & \multicolumn{2}{|c|}{ El-Awady } \\
\hline Slope & $\mathbf{R}^{2}$ & Slope & $\mathbf{R}^{2}$ & Slope & $\mathbf{R}^{2}$ & Slope & $\mathbf{R}^{2}$ \\
\hline 1.771 & 0.996 & -0.140 & 0.942 & -0.092 & 0.952 & -0.416 & 0.961 \\
\hline \multicolumn{8}{|c|}{ Parameters } \\
\hline $\mathrm{C}(\mathrm{g})$ & $\log C$ & In C & $\square$ & $\mathrm{C} / \square$ & $\log \square$ & $1-\square$ & $\log (\square / 1-\square)$ \\
\hline 15 & 1.1761 & 2.7081 & 0.7116 & 21.0793 & -0.1478 & 0.2884 & 0.3922 \\
\hline 30 & 1.4771 & 3.4012 & 0.6653 & 45.0924 & -0.1770 & 0.3347 & 0.2984 \\
\hline 45 & 1.6532 & 3.8067 & 0.6062 & 74.2329 & -0.2174 & 0.3938 & 0.1873 \\
\hline
\end{tabular}




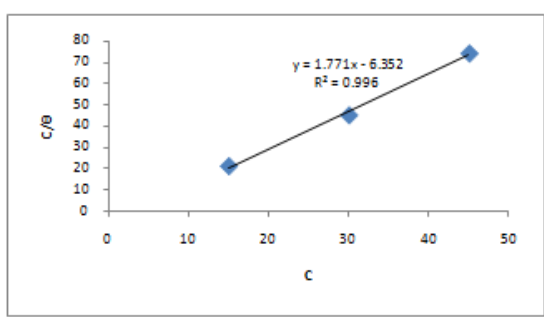

(a)

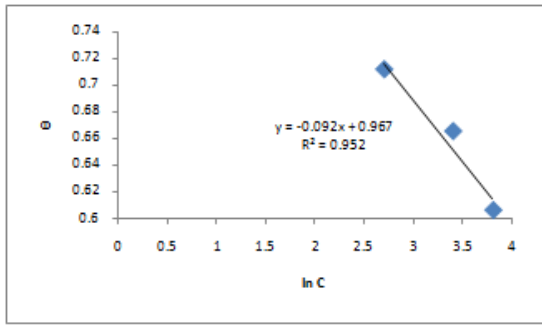

(c)

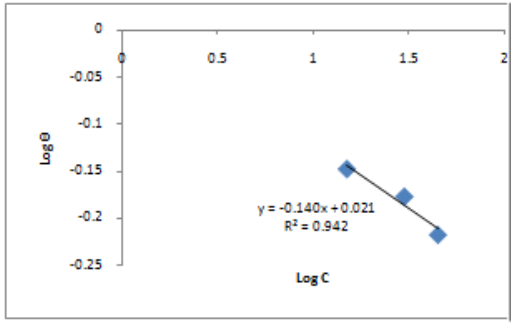

(b)

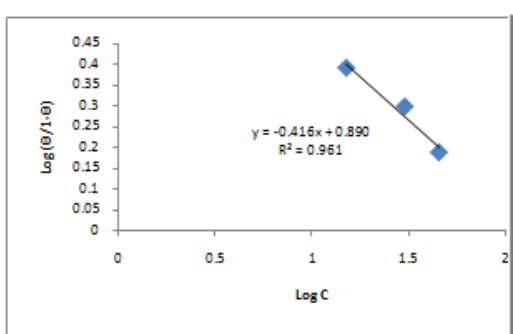

(d)

Figure 7: Adsorption isotherm models for adsorption of the thoroughly crushed fresh leaves of Sida Acuta on the mild steel surface in hydrochloric acid medium: (a) Langmuir Adsorption Isotherm; (b) Freundlich Adsorption Isotherm (c) Temkin Adsorption Isotherm (d) El-Awady Adsorption Isotherm

Table 7: Result of the phytochemical analysis conducted on Sida Acuta leaves

\begin{tabular}{|c|c|c|c|c|c|c|c|}
\hline \multirow{2}{*}{\multicolumn{2}{|c|}{$\begin{array}{l}\text { Plant } \\
\text { Leaf }\end{array}$}} & \multicolumn{6}{|c|}{ Compounds } \\
\hline & & $\begin{array}{l}\text { Saponin } \\
(96)\end{array}$ & $\begin{array}{l}\text { Tannin } \\
(06)\end{array}$ & $\begin{array}{l}\text { Flavonoid } \\
(86)\end{array}$ & $\begin{array}{l}\text { Alkanoid } \\
(90)\end{array}$ & $\begin{array}{l}\text { Phytate } \\
(96)\end{array}$ & $\begin{array}{l}\text { Phenol } \\
\text { (ppm) }\end{array}$ \\
\hline \multirow[t]{2}{*}{ Sida Acuta } & Dry & 1.73 & 1.522 & 2.50 & 4.00 & 0.717 & 22.19 \\
\hline & Fresh & 0.98 & 0.657 & 2.00 & 3.10 & 0.597 & 20.55 \\
\hline
\end{tabular}

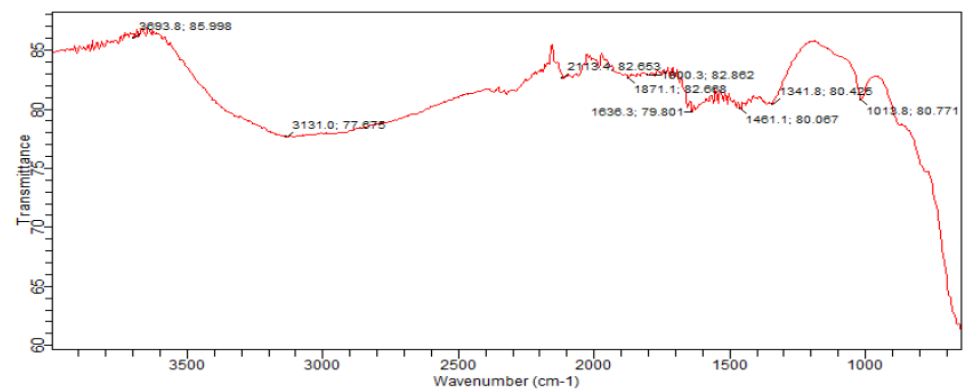

Figure 8: FTIR spectrum of film on mild steel surface after Immersion for eight hours in a medium containing the thoroughly crushed fresh leaves of Sida Acuta at $30 \mathrm{~g}$ per litre of $0.7 \mathrm{M} \mathrm{HCl}$

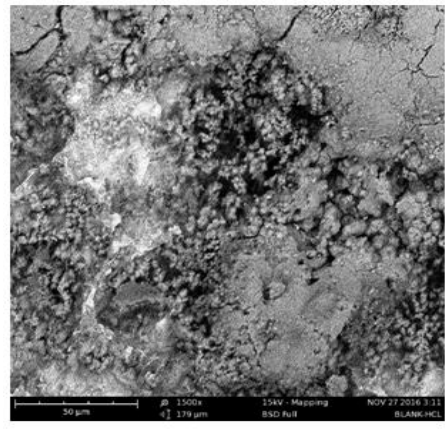

(a)

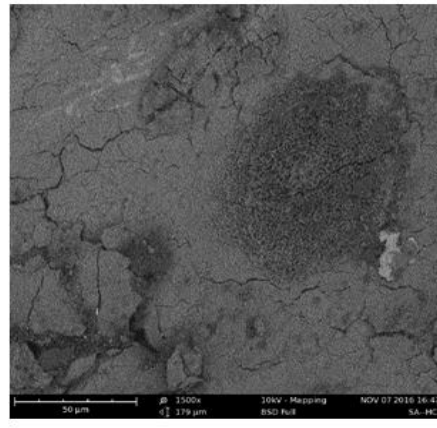

(b)

Figure 9: SEM characteristics of the corroded mild steel in; (a) the blank solution of $0.7 \mathrm{M} \mathrm{HCl} \mathrm{(b)} \mathrm{the} \mathrm{presence}$ of thoroughly pounded fresh leaves of Sida Acuta at $30 \mathrm{~g}$ per litre of $0.7 \mathrm{M} \mathrm{HCl}$ 


\section{Discussion of Results \\ 4.1 Effect of addition of thoroughly pounded fresh leaves of Sida Acuta on the corrosion of mild steel coupons immersed in hydrochloric acid solution}

The addition of thoroughly pounded leaves of Sida Acuta was observed to reduce the corrosion of mild steel coupons immersed in hydrochloric acid medium. When the pounded leaves were added at $15 \mathrm{~g}$ per litre of $0.7 \mathrm{M}, 1.2 \mathrm{M}$ and $2.2 \mathrm{M}$ acid concentrations, the following average corrosion rate, $\mathrm{CR}$ and inhibition efficiency, I.E were obtained in the order $C R(I . E)$ as presented in Table 1: $0.4839 \mathrm{mgcm}^{-2} \mathrm{~h}^{-1}(71.16 \%)$ in $0.7 \mathrm{M} \mathrm{HCl}$; $0.8110 \mathrm{mgcm}^{-2} \mathrm{~h}^{-1}(37.09 \%)$ in $1.2 \mathrm{M} \mathrm{HCl}$ and $1.5661 \mathrm{mgcm}^{-2} \mathrm{~h}^{-1}(35.58 \%)$ in $2.2 \mathrm{M} \mathrm{HCl}$. When the addition of the crushed fresh leaves of sida Acuta was increased to $30 \mathrm{~g}$ per litre of various acid concentrations, the corresponding average corrosion rate and inhibition efficiency were: $0.5603 \mathrm{mgcm}^{-2} \mathrm{~h}^{-1}(66.53 \%)$ in $0.7 \mathrm{M} \mathrm{HCl}$; $0.7081 \mathrm{mgcm}^{-2} \mathrm{~h}^{-1}(48.34 \%)$ in $1.2 \mathrm{M} \mathrm{HCl}$ and $1.3604 \mathrm{mgcm}^{-2} \mathrm{~h}^{-1}(47.81 \%)$ in $2.2 \mathrm{M} \mathrm{HCl}$. Further addition of the pounded fresh leaves of Sida Acuta at $45 \mathrm{~g}$ per litre of $0.7 \mathrm{M}, 1.2 \mathrm{M}$ and $2.2 \mathrm{M} \mathrm{HCl}$ gave the following average corrosion rate and inhibition efficiency: $0.6823 \mathrm{mgcm}^{-2} \mathrm{~h}^{-1}(60.62 \%)$ in $0.7 \mathrm{M} \mathrm{HCl} ; 0.5168 \mathrm{mgcm}^{-2} \mathrm{~h}^{-1}(62.96 \%)$ in $1.2 \mathrm{M} \mathrm{HCl}$ and $1.4164 \mathrm{mgcm}^{-2} \mathrm{~h}^{-1}(43.06 \%)$ in $2.2 \mathrm{M} \mathrm{HCl}$. The corrosion rate was observed to increase with increase in acid concentration. This development reveals that the corrosive environment becomes more aggressive as the concentration of acid is increased.

The corrosion rate-time curves for the mild steel coupons immersed in $0.7 \mathrm{M}, 1.2 \mathrm{M}$ and $2.2 \mathrm{M} \mathrm{HCl}$ with and without the addition of thoroughly crushed Sida Acuta's fresh leaves are shown in Figure 2. Generally, the corrosion rate curves were observed to progressively decrease with increase in time. Figure 3 shows the inhibition efficiency for the corrosion of mild steel coupons immersed in $0.7 \mathrm{M}, 1.2 \mathrm{M}$ and $2.2 \mathrm{M} \mathrm{HCl}$ as a result of the addition of crushed leaves of Sida Acuta at $15 \mathrm{~g}$ per litre, $30 \mathrm{~g}$ per litre and $45 \mathrm{~g}$ per litre of the acid concentration. The inhibition efficiency-time curve was observed to increase as the experimentation progressed. For the entire examined environment, the maximum inhibition efficiency of $71.16 \%$ was attained when the thoroughly pounded leaves of Sida Acuta were added at $15 \mathrm{~g}$ per litre of $0.7 \mathrm{M} \mathrm{HCl}$ whilst the corrosion rate reduced from 1.0485 to $0.3006 \mathrm{mgcm}^{-2} \mathrm{~h}^{-1}$.

\subsection{Prediction of corrosion inhibition of mild steel in hydrochloric acid medium by the thoroughly crushed leaves of Sida Acuta}

Multiple regression and artificial neural network were used to predict the corrosion rates of mild steel coupons in the presence and absence of thoroughly squeezed leaves of Sida Acuta in hydrochloric acid medium with the aid of the SPSS software. The predicted values are shown in Appendix 1.

Using multiple regression as illustrated in Table 2, the predictive equation for the addition of the crushed fresh leaves of Sida Acuta to the hydrochloric acid medium is stated thus:

$C R_{\text {SA in }}$ HClby $y \mathbb{R}=1.721-0.229$ (time) $+\mathbf{0 . 6 1 8}$ (conc. of acid) -0.019 (quantity of crushed leaves)

The prediction of the experimental corrosion rate by the artificial neural network reveals the importance of independent variables (time (h), concentration of acid (M) and quantity of crushed leaves $(\mathrm{g})$ ) in the prediction of the dependent variable (Corrosion rate, CR $\left(\mathrm{mgcm}^{-2} \mathrm{~h}^{-1}\right)$ for the addition of crushed leaves of Sida Acuta to the hydrochloric acid induced corrosion of mild steel as presented in Table 3. The time of exposure immensely contributed to the prediction of the corrosion rate by $48.9 \%$, followed by the quantity of crushed leaves, $26.2 \%$ and finally the concentration of acid, $25.0 \%$.

The comparison of error results for the prediction of corrosion inhibition of mild steel by the crushed leaves of Sida Acuta in hydrochloric acid medium using multiple regression and artificial neural network are presented in Table 4 and displayed in Figures 4 and 5. The results show that the predictions by the artificial neural network did not only give minimal errors but were closer to the experimental corrosion rate values in comparison with the predictions by multiple regression.

\subsection{Temperature dependence}

The result of the variation in temperature between $298 \mathrm{~K}$ and $358 \mathrm{~K}$ on the corrosion of mild steel without and with the addition of the crushed leaves of Sida Acuta at $15 \mathrm{~g}$ per litre of $0.7 \mathrm{M} \mathrm{HCl}$ agrees with the Arrhenius relationship and is presented in Table 5 and displayed in Figure 6. The activation energy for the corrosion of mild steel in the blank solution of $0.7 \mathrm{M} \mathrm{HCl}$ was $20,908.68 \mathrm{~J}$ whilst the addition of Sida Acuta's pounded leaves increased the activation energy to $28,088.86 \mathrm{~J}$. This higher value of activation energy obtained by the introduction of the crushed plant leaves to the corrodent reveals that higher energy needs to be attained before further corrosion can take place.

\subsection{Adsorption isotherm consideration}

Langmuir, Freundlich, Temkin and El-Awady adsorption isotherm models were tested and presented in Table 6 and Figure 7. The results show that the corrosion inhibition of mild steel in hydrochloric acid by the crushed leaves of Sida Acuta obeys all the aforementioned isotherm models with the Langmuir isotherm 
maintaining the best fit of $\mathrm{R}^{2}=0.996$; El-Awady, $\mathrm{R}^{2}=0.961$; Temkin, $\mathrm{R}^{2}=0.952$ and Freundlich, $\mathrm{R}^{2}=0.942$. Equations (9), (10), (11) and (12) illustrate these adsorption isotherm models (Adejo et al., 2013; Fadare et al., 2016).

Langmuir:

$$
\frac{c}{\theta}=C+\frac{1}{K}
$$

Freundlich:

$$
\log \Theta=\log K+\operatorname{nLog} C
$$

El-Awady:

$$
\log \left(\frac{\theta}{1-\theta}\right)=\log K+y \log C
$$

Temkin:

$$
\Theta=b \operatorname{In} A+b \ln C
$$

Where,

$\theta$ is the fraction of surface coverage,

$C$ is the inhibitor concentration,

$K$ is the equilibrium constant for the adsorption/desorption process, and

$b=$ Constant related to heat of sorption $(\mathrm{J} / \mathrm{mol})$.

\subsection{Phytochemical analysis of the leaves of Sida Acuta}

The phytochemical analysis of Sida Acuta's leaves as illustrated in Table 7 indicates the presence of alkanoid (4.0\%), tannin (1.522\%), saponin (1.73\%), phytate $(0.717 \%)$, flavonoid $(2.50 \%)$ and phenol $(22.19 \mathrm{ppm})$. These natural constituents may be responsible for adsorbing on the surface of the mild steel thereby effecting corrosion inhibition.

\subsection{FTIR analysis}

Figure 8 shows the FTIR spectrum of the protective film that adhered on the surface of mild steel coupon owing to the addition of the crushed leaves of Sida Acuta at $30 \mathrm{~g}$ per litre of $0.7 \mathrm{M} \mathrm{HCl}$ for eight hours. The strong band at $3693.8 \mathrm{~cm}^{-1}$ reveals the functional group of hydrogen atom bonded to oxygen atom $(\mathrm{O}-\mathrm{H}$ stretching vibration). The strong bands at frequencies $2113.4 \mathrm{~cm}^{-1}, 1871.1 \mathrm{~cm}^{-1}$ and $1636.3 \mathrm{~cm}^{-1}$ indicate the presence of $\mathrm{C} \equiv \mathrm{C}, \mathrm{C}=\mathrm{O}$ and $\mathrm{C}=\mathrm{C}$ stretching vibrations of alkynes, acid anhydride and alkene respectively. $\mathrm{CH}_{2}$ bending is also spotted around $1461.1 \mathrm{~cm}^{-1}$.

\subsection{SEM micrograph for the corrosion inhibition of mild steel in $\mathrm{HCl}$ solution by the crushed leaves of Sida Acuta}

Figure 9(a) shows the SEM image of the corrosion of mild steel in an uninhibited solution of $0.7 \mathrm{M}$ $\mathrm{HCl}$. Corrosion was observed not to take place identically over the surface of the steel. However, the addition of the crushed fresh leaves of Sida Acuta at $30 \mathrm{~g}$ per litre of $0.7 \mathrm{M} \mathrm{HCl}$ clearly protected the surface of the steel from corrosion as shown in Figure 9(b) in comparison with the inhibitor-free solution.

\section{CONCLUSION}

1. The corrosion rate was observed to increase with increase in acid concentration.

2. The maximum inhibition efficiency of $71.16 \%$ was attained when the thoroughly pounded leaves of Sida Acuta were added at $15 \mathrm{~g}$ per litre of $0.7 \mathrm{M} \mathrm{HCl}$ whilst the corrosion rate reduced from 1.0485 to $0.3006 \mathrm{mgcm}^{-2} \mathrm{~h}^{-1}$.

3. Predictions by the artificial neural network gave minimal errors and were closer to the experimental corrosion rate values in comparison with the predictions by multiple regression.

4. The corrosion inhibition of mild steel in hydrochloric acid by the crushed leaves of Sida Acuta obeys all the four tested adsorption isotherm models with the Langmuir isotherm maintaining the best fit of $\mathrm{R}^{2}=0.996$; El-Awady, $\mathrm{R}^{2}=0.961$; Temkin, $\mathrm{R}^{2}=0.952$ and Freundlich, $\mathrm{R}^{2}=0.942$.

5. The FTIR analysis revealed that the adsorbed constituents of the crushed leaves of Sida Acuta on the surface of mild steel are associated with the stretching vibrations of $\mathrm{C} \equiv \mathrm{C}, \mathrm{C}=\mathrm{C}, \mathrm{C}=\mathrm{O}$ and $\mathrm{O}-\mathrm{H}$ bonds.

6. The SEM image shows that the degradation of the surface of mild steel in an uninhibited $0.7 \mathrm{M} \mathrm{HCl}$ solution is localized. However, the addition of Sida Acuta's crushed leaves remarkably prevented the surface of the steel from corrosion.

\section{REFERENCES}

[1]. Patni, N., Agarwal, S. \& Shah, P. (2013). Greener Approach towards Corrosion Inhibition, Review Article. Chinese Journal of Engineering, Hindawi Pub-lishing Coorporation, vol. 2013, p. 1-10.

[2]. Jones, L. \& Atkins, P. (2000). Chemistry - Molecules, Matter, and Change, $4^{\text {th }}$ Edition. New York: W. H. Freeman Company, p. $821-822$.

[3]. Fadare, O. O., Okoronkwo, A. E. \& Olasehinde, E. F. (2016). Assessment of Anti-Corrosion Potential of extract of Ficus Asperifolia-Miq (Moraceae) on mild steel in acid medium. African Journal of Pure and Applied Chemistry, 10(1) 8-22. 
[4]. Adejo, S. O., Yiase, S. G., Ahile, U. J., Tyohemba, T. G. \& Gbertyo, J. A. (2013). Inhibitory effect and adsorption parameters of extract of leaves of Portulacaoleracea of corrosion of aluminium in $\mathrm{H}_{2} \mathrm{SO}_{4}$ solution. Archives of Applied Science Research, $\mathbf{5}(1)$ : 25-32

[5]. Anyakwo, C. N. (2007). Inhibition of corrosion of mild steel in hydrochloric acid by the leaf juice of chanca piedra (Phyllanthus niruri) plant. Jour. of Eng. and Applied Sci. (AJER) 3, 8-14.

[6]. Ayeni, F. A., Alawode, S., Joseph, D., Sukop, P., Olawuyi, V., Alonge, T. E., Alabi, O. O., Oluwabunmi, O. \& Alo, F. I. (2014). Investigation of Sida acuta (Wire Weed) Plant Extract as Corrosion Inhibitor for Aluminium-Copper-Magnessium Alloy in Acidic Medium. Journal of Minerals and Materials Characterization and Engineering, 2, $286-291$. http://dx.doi.org/10.4236/jmmce.2014.24033

[7]. Flanagan, G. J., Hills, L. A., \& Wilson, C. G. (2000). The successful biological control of spinyhead Sida, Sida acuta (Malvaceae), by Calligrapha pantherina (Col: Chrysomelidae) in Australia's Northern Territory. In: Proceedings of the X International Symposium on Biological Control of Weeds, Bozeman, Montana, USA, 4-14 July, 1999 [ed. by Spencer, N. R.]. Bozeman, USA: Montana State University, 35-41

[8]. Lonsdale W. M., Farrell G., \& Wilson C. G. (1995). Biological Control of a Tropical Weed: A Population Model and Experiment for Sida Acuta. Journal of Applied Ecology, 32(2):391-399.

[9]. Pitt, J. L. (1992). Spinyhead sida (Sida acuta). Agnote (Darwin), No. 496, pp 2.

[10]. Raja, P. B., \& Sethuraman, M. G. (2008). Inhibitive effect of black pepper extract on the sulphuric acid corrosion of mild steel. J. Mat., 62 (17-18) 2977-2979.

[11]. Rojas-Sandoval, J., Acevedo-Rodriguez, P., \& Clements, David (2009). Sida Acuta. Retrieved June 16, 2015, from http://www. cabi.org/isc/datasheet/49985

[12]. Ayer, T., Chhatwal, J., Alagoz, O., Kahn, C. E., Woods, R. W. \& Burnside, E.S. (2010). Informatics in Radiology: Comparison of Logistic Regression and Artificial Neural Network Models in Breast Cancer Risk Estimation. Retrieved October 11, 2016 from https://www.ncbi.nlm.gov/pmc/articles/PMC3709515

[13]. Bellomo, N., De Angelis, E. \& Delitala, M. (2007). Lecture notes on mathematical modelling in applied sciences. Retrieved June 16, 2015, from http://www. staff.polito.it/../mechanic_Simai.pdf

[14]. Han, J., Kamber, M. \& Pei, J. (2012). Data Mining, Third Edition. USA: Elsevier Inc. P. 398

[15]. Higgins, J. (2005). Introduction to Multiple Regression. Excerpted from The Radical Statistician. Retrieved from http://www.biddle.com/documents/bcg_comp_chapter4.pdf

[16]. Lærd Statistics (2013). Multiple Regression Analysis using SPSS Statistics. Retrieved September 20, 2016 from https://statistics.laerd.com/spss-tutorials/multiple-regression-using-spss-statistics.php

[17]. Mean Absolute Error (2016). The Mean Absolute Error. Retrieved September 19, 2016 from https://en.m.wikipedia.org/wiki/mean_absolute_error

[18]. Mean Squared Error and Residual Sum of Squares (2013). Cross Validation. Retrieved September 20, 2016 from http://stats.stackexchange.com/questions/73540/mean-squared-error-and-residual-sum-of-squares

[19]. Okoro, O. I. (2008). Introduction to MATLAB/SIMULINK for Engineers and Scientists (2 ${ }^{\text {nd }}$ ed., p. 2). Enugu: John Jacob's Classic.

[20]. Sykes, A. O. (1992). An Introduction to Regression Analysis. The Inaugural Coarse Lecture of The University of Chicago. Retrieved March 2, 2016 from http://m.law.uchicago.edu/node/1309

Appendix 1: Prediction of corrosion inhibition of mild steel in hydrochloric acid medium by thoroughly crushed leaves of Sida Acuta

\begin{tabular}{|c|c|c|c|c|c|c|c|c|}
\hline \multirow[t]{2}{*}{ Case } & \multirow{2}{*}{$\begin{array}{l}\text { Time } \\
\text { (h) }\end{array}$} & \multirow{2}{*}{$\begin{array}{l}\begin{array}{c}\text { Conc_of } \\
\mathrm{HCl}\end{array} \\
\text { (M) }\end{array}$} & \multirow{2}{*}{$\begin{array}{l}\text { Quantity_ } \\
\text { of_SA_Cr } \\
\text { ushed_Le } \\
\text { aves } \\
\text { (g) }\end{array}$} & \multirow{2}{*}{$\begin{array}{c}\text { Exp. } \\
\text { Corrosion } \\
\text { Rate, CR } \\
\left(\mathrm{mgcm}^{-2} \mathrm{~h}^{-1}\right)\end{array}$} & \multicolumn{2}{|c|}{ Prediction_by_MR } & \multicolumn{2}{|c|}{ Prediction_by_ANN } \\
\hline & & & & & CR & Error & CR & Error \\
\hline 1 & 1 & 0.7 & $\begin{array}{l}0 \\
\end{array}$ & 2.6487 & 1.9249 & 0.7238 & 1.6707 & 0.978 \\
\hline 2 & 2 & 0.7 & 0 & 1.8646 & 1.6961 & 0.1685 & 1.2657 & 0.5989 \\
\hline 3 & 3 & 0.7 & 0 & 1.3989 & 1.4673 & -0.0684 & 1.143 & 0.2559 \\
\hline 4 & 4 & 0.7 & 0 & 1.4137 & 1.2386 & 0.1751 & 1.1171 & 0.2966 \\
\hline 5 & 5 & 0.7 & 0 & 1.4214 & 1.0098 & 0.4116 & 1.1245 & 0.2969 \\
\hline 6 & 6 & 0.7 & 0 & 1.3684 & 0.7810 & 0.5874 & 1.1433 & 0.2251 \\
\hline 7 & 7 & 0.7 & 0 & 1.3924 & 0.5522 & 0.8402 & 1.1657 & 0.2267 \\
\hline 8 & 8 & 0.7 & 0 & 1.3934 & 0.3235 & 1.0699 & 1.1888 & 0.2046 \\
\hline 9 & 1 & 0.7 & 15 & 1.0485 & 1.6408 & -0.5923 & 1.0049 & 0.0436 \\
\hline 10 & 2 & 0.7 & 15 & 0.5925 & 1.4120 & -0.8195 & 0.7331 & -0.1406 \\
\hline 11 & 3 & 0.7 & 15 & 0.4608 & 1.1833 & -0.7225 & 0.6556 & -0.1948 \\
\hline 12 & 4 & 0.7 & 15 & 0.4378 & 0.9545 & -0.5167 & 0.6397 & -0.2019 \\
\hline 13 & 5 & 0.7 & 15 & 0.4037 & 0.7257 & -0.3220 & 0.6452 & -0.2415 \\
\hline 14 & 6 & 0.7 & 15 & 0.3006 & 0.4970 & -0.1964 & 0.6591 & -0.3585 \\
\hline 15 & 7 & 0.7 & 15 & 0.3145 & 0.2682 & 0.0463 & 0.6767 & -0.3622 \\
\hline 16 & 8 & 0.7 & 15 & 0.3129 & 0.0394 & 0.2735 & 0.6963 & -0.3834 \\
\hline 17 & 1 & 0.7 & 30 & 1.1792 & 1.3567 & -0.1775 & 0.8017 & 0.3775 \\
\hline 18 & 2 & 0.7 & 30 & 0.7275 & 1.1280 & -0.4005 & 0.5636 & 0.1639 \\
\hline 19 & 3 & 0.7 & 30 & 0.4724 & 0.8992 & -0.4268 & 0.4932 & -0.0208 \\
\hline 20 & 4 & 0.7 & 30 & 0.4821 & 0.6704 & -0.1883 & 0.4722 & 0.0099 \\
\hline 21 & 5 & 0.7 & 30 & 0.4200 & 0.4417 & -0.0217 & 0.4673 & -0.0473 \\
\hline 22 & 6 & 0.7 & 30 & 0.4478 & 0.2129 & 0.2349 & 0.4682 & -0.0204 \\
\hline 23 & 7 & 0.7 & 30 & 0.3946 & -0.0159 & 0.4105 & 0.4714 & -0.0768 \\
\hline 24 & 8 & 0.7 & 30 & 0.3590 & -0.2447 & 0.6037 & 0.4756 & -0.1166 \\
\hline 25 & 1 & 0.7 & 45 & 1.8210 & 1.0727 & 0.7483 & 0.8123 & 1.0087 \\
\hline
\end{tabular}


Modelling of Corrosion Inhibition of Mild Steel in Hydrochloric...

\begin{tabular}{|c|c|c|c|c|c|c|c|c|}
\hline 26 & 2 & 0.7 & 45 & 0.7667 & 0.8439 & -0.0772 & 0.5461 & 0.2206 \\
\hline 27 & 3 & 0.7 & 45 & 0.7087 & 0.6151 & 0.0936 & 0.4673 & 0.2414 \\
\hline 28 & 4 & 0.7 & 45 & 0.6190 & 0.3864 & 0.2326 & 0.4423 & 0.1767 \\
\hline 29 & 2 & 0.7 & 45 & 0.4740 & 0.7982 & -0.3242 & 0.5222 & -0.0482 \\
\hline 30 & 6 & 0.7 & 45 & 0.4903 & -0.0712 & 0.5615 & 0.4318 & 0.0585 \\
\hline 31 & 7 & 0.7 & 45 & 0.3118 & -0.2999 & 0.6117 & 0.4314 & -0.1196 \\
\hline 32 & 8 & 0.7 & 45 & 0.2672 & -0.5287 & 0.7959 & 0.4318 & -0.1646 \\
\hline 33 & 1 & 1.2 & 0 & 2.2857 & 2.2341 & 0.0516 & 2.6014 & -0.3157 \\
\hline 34 & 2 & 1.2 & 0 & 1.5683 & 2.0053 & -0.4370 & 1.6442 & -0.0759 \\
\hline 35 & 3 & 1.2 & 0 & 1.1109 & 1.7765 & -0.6656 & 1.2976 & -0.1867 \\
\hline 36 & 4 & 1.2 & 0 & 1.1753 & 1.5477 & -0.3724 & 1.1938 & -0.0185 \\
\hline 37 & 5 & 1.2 & 0 & 1.1838 & 1.3190 & -0.1352 & 1.1733 & 0.0105 \\
\hline 38 & 6 & 1.2 & 0 & 1.0470 & 1.0902 & -0.0432 & 1.1815 & -0.1345 \\
\hline 39 & 7 & 1.2 & 0 & 1.0447 & 0.8614 & 0.1833 & 1.1993 & -0.1546 \\
\hline 40 & 8 & 1.2 & 0 & 0.9276 & 0.6327 & 0.2949 & 1.2200 & -0.2924 \\
\hline 41 & 1 & 1.2 & 15 & 1.4638 & 1.9500 & -0.4862 & 1.7128 & -0.2490 \\
\hline 42 & 2 & 1.2 & 15 & 0.9018 & 1.7212 & -0.8194 & 0.9822 & -0.0804 \\
\hline 43 & 3 & 1.2 & 15 & 0.7803 & 1.4924 & -0.7121 & 0.7524 & 0.0279 \\
\hline 44 & 4 & 1.2 & 15 & 0.7065 & 1.2637 & -0.5572 & 0.6887 & 0.0178 \\
\hline 45 & 5 & 1.2 & 15 & 0.6901 & 1.0349 & -0.3448 & 0.6788 & 0.0113 \\
\hline 46 & 6 & 1.2 & 15 & 0.6999 & 0.8061 & -0.1062 & 0.6881 & 0.0118 \\
\hline 47 & 7 & 1.2 & 15 & 0.6647 & 0.5774 & 0.0873 & 0.7050 & -0.0403 \\
\hline 48 & 8 & 1.2 & 15 & 0.5805 & 0.3486 & 0.2319 & 0.7253 & -0.1448 \\
\hline 49 & 1 & 1.2 & 30 & 1.7106 & 1.6659 & 0.0447 & 1.3842 & 0.3264 \\
\hline 50 & 2 & 1.2 & 30 & 0.8103 & 1.4372 & -0.6269 & 0.745 & 0.0653 \\
\hline 51 & 3 & 1.2 & 30 & 0.6089 & 1.2084 & -0.5995 & 0.5524 & 0.0565 \\
\hline 52 & 4 & 1.2 & 30 & 0.7740 & 0.9796 & -0.2056 & 0.4953 & 0.2787 \\
\hline 53 & 5 & 1.2 & 30 & 0.5826 & 0.7508 & -0.1682 & 0.4789 & 0.1037 \\
\hline 54 & 6 & 1.2 & 30 & 0.4811 & 0.5221 & -0.0410 & 0.4762 & 0.0049 \\
\hline 55 & 7 & 1.2 & 30 & 0.3502 & 0.2933 & 0.0569 & 0.4784 & -0.1282 \\
\hline 56 & 8 & 1.2 & 30 & 0.3471 & 0.0645 & 0.2826 & 0.4827 & -0.1356 \\
\hline 57 & 1 & 1.2 & 45 & 1.2359 & 1.3819 & -0.1460 & 1.4350 & -0.1991 \\
\hline 58 & 2 & 1.2 & 45 & 0.9221 & 1.1531 & -0.2310 & 0.7369 & 0.1852 \\
\hline 59 & 3 & 1.2 & 45 & 0.3892 & 0.9243 & -0.5351 & 0.5252 & -0.1360 \\
\hline 60 & 4 & 1.2 & 45 & 0.2316 & 0.6956 & -0.4640 & 0.4617 & -0.2301 \\
\hline 61 & 5 & 1.2 & 45 & 0.3694 & 0.4668 & -0.0974 & 0.4414 & -0.0720 \\
\hline 62 & 6 & 1.2 & 45 & 0.4013 & 0.2380 & 0.1633 & 0.4350 & -0.0337 \\
\hline 63 & 7 & 1.2 & 45 & 0.317 & 0.0092 & 0.3078 & 0.4333 & -0.1163 \\
\hline 64 & 8 & 1.2 & 45 & 0.2676 & -0.2195 & 0.4871 & 0.4333 & -0.1657 \\
\hline 65 & 1 & 2.2 & 0 & 5.9626 & 2.8524 & 3.1102 & 4.9762 & 0.9864 \\
\hline 66 & 2 & 2.2 & 0 & 3.5723 & 2.6236 & 0.9487 & 3.7766 & -0.2043 \\
\hline 67 & 3 & 2.2 & 0 & 2.4367 & 2.3949 & 0.0418 & 2.3381 & 0.0986 \\
\hline 68 & 4 & 2.2 & 0 & 1.9052 & 2.1661 & -0.2609 & 1.6102 & 0.2950 \\
\hline 69 & 5 & 2.2 & 0 & 1.5683 & 1.9373 & -0.3690 & 1.3596 & 0.2087 \\
\hline 70 & 6 & 2.2 & 0 & 1.3462 & 1.7086 & -0.3624 & 1.2859 & 0.0603 \\
\hline 71 & 7 & 2.2 & 0 & 1.2016 & 1.4798 & -0.2782 & 1.2732 & -0.0716 \\
\hline 72 & 8 & 2.2 & 0 & 1.1519 & 1.2510 & -0.0991 & 1.2812 & -0.1293 \\
\hline 73 & 1 & 2.2 & 15 & 4.1154 & 2.5684 & 1.5470 & 4.2585 & -0.1431 \\
\hline 74 & 2 & 2.2 & 15 & 2.2973 & 2.3396 & -0.0423 & 2.8500 & -0.5527 \\
\hline 75 & 3 & 2.2 & 15 & 1.5393 & 2.1108 & -0.5715 & 1.5276 & 0.0117 \\
\hline 76 & 4 & 2.2 & 15 & 1.2082 & 1.882 & -0.6738 & 0.9817 & 0.2265 \\
\hline 77 & 5 & 2.2 & 15 & 0.9921 & 1.6533 & -0.6612 & 0.8160 & 0.1761 \\
\hline 78 & 6 & 2.2 & 15 & 0.8766 & 1.4245 & -0.5479 & 0.7747 & 0.1019 \\
\hline 79 & 7 & 2.2 & 15 & 0.756 & 1.1957 & -0.4397 & 0.7754 & -0.0194 \\
\hline 80 & 8 & 2.2 & 15 & 0.7435 & 0.9670 & -0.2235 & 0.7915 & -0.0480 \\
\hline 81 & 1 & 2.2 & 30 & 3.9847 & 2.2843 & 1.7004 & 3.6928 & 0.2919 \\
\hline 82 & 2 & 2.2 & 30 & 2.0853 & 2.0555 & 0.0298 & 2.2747 & -0.1894 \\
\hline 83 & 3 & 2.2 & 30 & 1.3205 & 1.8268 & -0.5063 & 1.1072 & 0.2133 \\
\hline 84 & 4 & 2.2 & 30 & 1.0615 & 1.5980 & -0.5365 & 0.6734 & 0.3881 \\
\hline 85 & 5 & 2.2 & 30 & 0.8051 & 1.3692 & -0.5641 & 0.5458 & 0.2593 \\
\hline 86 & 6 & 2.2 & 30 & 0.6583 & 1.1404 & -0.4821 & 0.5086 & 0.1497 \\
\hline 87 & 7 & 2.2 & 30 & 0.5145 & 0.9117 & -0.3972 & 0.4999 & 0.0146 \\
\hline 88 & 8 & 2.2 & 30 & 0.4531 & 0.6829 & -0.2298 & 0.5013 & -0.0482 \\
\hline 89 & 1 & 2.2 & 45 & 4.0341 & 2.0002 & 2.0339 & 3.6514 & 0.3827 \\
\hline 90 & 2 & 2.2 & 45 & 1.8544 & 1.7715 & 0.0829 & 2.2930 & -0.4386 \\
\hline 91 & 3 & 2.2 & 45 & 1.3457 & 1.5427 & -0.1970 & 1.0923 & 0.2534 \\
\hline 92 & 4 & 2.2 & 45 & 1.1726 & 1.3139 & -0.1413 & 0.6317 & 0.5409 \\
\hline 93 & 5 & 2.2 & 45 & 0.9416 & 1.0851 & -0.1435 & 0.4968 & 0.4448 \\
\hline 94 & 6 & 2.2 & 45 & 0.8694 & 0.8564 & 0.0130 & 0.4553 & 0.4141 \\
\hline 95 & 7 & 2.2 & 45 & 0.5846 & 0.6276 & -0.0430 & 0.4421 & 0.1425 \\
\hline 96 & 8 & 2.2 & 45 & 0.5290 & 0.3988 & 0.1302 & 0.4384 & 0.0906 \\
\hline
\end{tabular}

